\title{
Importance of genetic diagnosis in the management of early-onset epilepsies
}

\section{Epilepsy in Africa}

Sub-Saharan Africa (SSA) carries the greatest burden of epilepsy in the world, exacerbated by the high incidence of central nervous system infections, perinatal insults and traumatic brain injury. ${ }^{[1]}$ Almost $60 \%$ of people with epilepsy in SSA do not receive medication, and only about a third of those who do are appropriately managed. ${ }^{[2]}$ The substantial risk of premature mortality associated with epilepsy in Africa (22.2 - 45.1 per $\left.1000^{[3]}\right)$ is strongly linked to poor seizure control. Reduced access to education and employment opportunities, as well as the social stigma attached to epilepsy in some communities, all place a burden on the individual and the family. The period of infancy carries the highest incidence of epilepsy, ${ }^{[4]}$ with some of the worst immediate and long-term sequelae affecting all areas of the infants' and their carers' lives. Early diagnosis and correct management are critical in mitigating the detrimental effects of uncontrolled seizures on the maturing brain. ${ }^{[5]}$

Most epilepsies previously termed 'idiopathic' (i.e. without a clear acquired cause) have a genetic basis. ${ }^{[6]}$ The advent of nextgeneration sequencing (NGS) created a massive surge in epilepsy gene discovery, revealing a previously unappreciated genetic and phenotypic heterogeneity. Over 350 genes have been associated with epilepsy to date, ${ }^{[7]}$ with a remarkably high frequency of de novo variants, especially among the developmental and epileptic encephalopathies (DEEs) ${ }^{[8]}$. Large-scale studies continue to expand and refine the phenotypic spectrum of known epilepsy-associated genes, with certain clinical features linked to variants in specific genes. ${ }^{[9]}$ Examples include movement disorders and head stereotypies in STXBP1-related DEE ${ }^{[10]}$ and clustered focal seizures restricted to females with $\mathrm{PCDH} 19$ variants. ${ }^{[1]}$ The genetic and phenotypic heterogeneity of epilepsy is exemplified by the SCN1A seizure disorders, where SCN1A variants may cause a severe, drug-resistant DEE (Dravet syndrome (DS) $)^{[12]}$ in some patients, or milder disease in others (e.g. generalised epilepsy with febrile seizures plus $($ GEFS +$))^{.[13]}$ The precise determinants of this heterogeneity are still unknown, but somatic mosaicism and functional effects of specific variants are known to play a role. ${ }^{[14]}$ Importantly, knowledge of the causative mutation may guide the choice of treatment. Examples of precision therapies include the ketogenic diet for glucose transporter deficiency (SLC2A1), phenytoin or high-dose carbamazepine for SCN2A and SCN8A, and avoidance of sodium channel blockers in $S C N 1 A$-related epilepsy. ${ }^{[15]}$ Genetic testing for epilepsy is now firmly embedded in the diagnostic setting of high-income counties (HICs), particularly for the DEEs, where the rate of informative findings is highest, with a demonstrable utility and cost benefit. ${ }^{[16,17]}$

A recent global burden of disease report ranked idiopathic epilepsy' (epilepsy of genetic origin or without a definite structural, metabolic, infective or immune cause) as the second most common neurological disorder in southern SSA. ${ }^{[18]}$ Yet little is known about the genetic architecture of epilepsy in SSA, and no genetic testing is available locally. ${ }^{[19]}$ While local research may uncover new genes and variants, it is likely that the genetic aetiology of de novo epilepsies in Africa is similar to the HICs. Research and translation in this instance should therefore happen almost simultaneously. Unfortunately, the expense of genomic analysis is a major limitation, as the anticipated reduction in NGS cost has not materialised tangibly in Africa. Suppliers base price negotiations on projected throughput, which is difficult in a setting of limited budget for genetic services, particularly in a state sector overwhelmed by the burden of infectious diseases. Paradoxically, it is often cheaper to refer NGS analyses abroad than to test locally, which presents an economical solution initially but does not serve to build local capacity. The shortage of suitably qualified workforce could be remedied by investment in training and creative use of the existing infrastructure, but requires buy-in and financial support from the health authorities.

\section{Opportunities: Research and translation in SA}

Initiatives such as H3Africa aim to address the deficits in genomic knowledge and capacity in Africa. Major emphasis lies on developing 'hubs' for research, bioinformatic networks and biorepositories across the continent. ${ }^{[2]}$ The exceptional genetic diversity of the African populations carries a far greater power of discovery than the more homogenous populations that form the basis of current knowledge. For instance, a recent case-control study involving 900 African patients revealed significant enrichment for rare variants in constrained genes in individuals with schizophrenia, with a modest effect size. ${ }^{[21]}$ Even though schizophrenia may be more heterogenous, three times as many patients of European ancestry were required to show a similar effect size in a study of generalised genetic epilepsy. ${ }^{[17]}$ Research in Africa may not only identify novel genes and mechanisms, but also influence development of new therapeutic agents for the benefit of patients everywhere.

With this in mind, the Division of Human Genetics at the University of Cape Town and the paediatric neurology team at Red Cross War Memorial Children's Hospital (RCWMCH), in collaboration with the Ken and Ruth Davee Department of Neurology at Northwestern University in Chicago, have initiated research into the genetic causes of epilepsies in SA children. The rationale for this ongoing work combines the need to build knowledge on epilepsy genetics in SA and create a basis for diagnostic testing. Most of the participants are children with DEE attending the epilepsy clinic at RCWMCH. The US collaboration lends valuable access to expertise in epilepsy genetics and NGS experimental design, helping to build capacity that is still centred in Africa. The project was successfully piloted with a subgroup of patients diagnosed with possible DS. The outcome not only helped to confirm or exclude DS, but also highlighted the onset of recurrent, prolonged febrile seizures before the age of 6 months as a simple diagnostic criterion for possible DS, useful in the resourceconstrained African setting. ${ }^{[22]}$ Correlating genetic findings with the phenotypic and electroclinical information in the main study participants has helped to refine the diagnoses and treatment in some cases, and detection of rare, novel variants has ended the 'diagnostic odyssey' for others, confirming the utility of testing.

The world and SA, albeit less robustly, have entered the age of genomics and precision medicine. However, full participation in this transition for the benefit of African patients requires investment into high-throughput genomic skills and platforms.

Ethics. The epilepsy research referred to in this editorial was approved by the Human Research Ethics Committee at the University of Cape Town (ref. nos 232/2015, 767/2017, 357/2019). 
Acknowledgements. We thank all the patients and parents for participation in the study. We are also grateful to the staff in the Epilepsy Clinic at RCWMCH for the work that went into patient recruitment and obtaining informed consent.

Funding. The epilepsy research referred to in this editorial is supported by the National Health Laboratory Service Research Trust (004-94528, 004-94491), the South African Medical Research Council (SAMRC SIR GRANT UO24508, the SAMRC Strategic Health Innovation Partnerships (SHIP) Unit, and funding to the SAMRC/UCT Genomic and Precision Medicine Research Unit).

\section{Alina I Esterhuizen}

South African Medical Research Council/University of Cape Town Genomic and Precision Medicine Research Unit, Division of Human Genetics, Institute of Infectious Diseases and Molecular Medicine, Department of Pathology, Faculty of Health Sciences, University of Cape Town, South Africa; and National Health Laboratory Service, Groote Schuur Hospital, Cape Town, South Africa alina.esterhuizen@uct.ac.za

\section{Gemma L Carvill}

Ken and Ruth Davee Department of Neurology, Feinberg School of Medicine, Northwestern University, Chicago, Ill., USA

\section{Karen Fieggen}

Division of Human Genetics, Department of Medicine, Faculty of Health Sciences, University of Cape Town and Groote Schuur Hospital, Cape Town, South Africa

\section{Caitlin McIntosh}

Division of Human Genetics, Institute of Infectious Diseases and Molecular Medicine, Department of Pathology, Faculty of Health Sciences, University of Cape Town, South Africa

\section{Rajkumar S Ramesar}

South African Medical Research Council/University of Cape Town Genomic and Precision Medicine Research Unit, Division of Human Genetics, Institute of Infectious Diseases and Molecular Medicine, Department of Pathology, Faculty of Health Sciences, University of Cape Town, South Africa; and National Health Laboratory Service, Groote Schuur Hospital, Cape Town, South Africa

\section{Jo M Wilmshurst}

Paediatric Neurology and Neurophysiology, Red Cross War Memorial Children's Hospital, Cape Town, South Africa; and School of Child and Adolescent Health, Faculty of Health Sciences, University of Cape Town, South Africa

1. Ngugi AK, Bottomley C, Kleinschmidt I, et al. Prevalence of active convulsive epilepsy in sub-Saharan Africa and associated risk factors: Cross-sectional and case-control studies. Lancet Neurol 2013;12:253263. https://doi.org/10.1016/S1474-4422(13)70003-6

2. Ba-Diop A, Marin BB, Druet-Cabanac M, Ngoungou EB, Newton CR, Preux P-MM. Epidemiology, causes, and treatment of epilepsy in sub-Saharan Africa. Lancet Neurol 2014;13(10):1029-1044. https:// doi.org/10.1016/S1474-4422(14)70114-0

3. Levira F, Thurman DJ, Sander JW, et al. Premature mortality of epilepsy in low- and middle-income countries: A systematic review from the Mortality Task Force of the International League Against Epilepsy. Epilepsia 2017;58(1):6-16. https://doi.org/10.1111/epi.13603

4. Wilmshurst JM, Gaillard WD, Vinayan KP, et al. Summary of recommendations for the management of infantile seizures: Task Force Report for the ILAE Commission of Pediatrics. Epilepsia 2015;56(8):11851197. https://doi.org/10.1111/epi.13057

5. Wilmshurst JM, Kakooza-Mwesige A, Newton CR. The challenges of managing children with epilepsy in Africa. Semin Pediatr Neurol 2014;21(1):36-41. https://doi.org/10.1016/.jspen.2014.01.005

6. Thomas RH, Berkovic SF. The hidden genetics of epilepsy - a clinically important new paradigm. Nat Rev 6. Thomas RH, Berkovic SF. The hidden genetics of epilepsy - a clinically in
Neurol 2014;10(5):283-292. https:///oi.org/10.1038/nrneurol.2014.62

7. Symonds JD, McTague A. Epilepsy and developmental disorders: Next generation sequencing in the clinic. Eur J Paediatr Neurol 2020;24:15-23. https://doi.org/10.1016/j.ejpn.2019.12.008

8. Allen AS, Berkovic SF, Cossette P, et al. De novo mutations in epileptic encephalopathies. Nature 2013;501(7466):217-221. https://doi.org/10.1038/nature12439

9. Happ HC, Carvill GL. A 2020 view on the genetics of developmental and epileptic encephalopathies. Epilepsy Curr 2020;20(2):90-96. https://doi.org/10.1177/1535759720906118

0. Di Meglio C, Lesca G, Villeneuve N, et al. Epileptic patients with de novo STXBP1 mutations: Key clinical features based on 24 cases. Epilepsia 2015;56(12):1931-1940. https://doi.org/10.1111/epi.13214 11. Marini C, Darra F, Specchio N, et al. Focal seizures with affective symptoms are a major feature of
PCDH19 gene-related epilepsy. Epilepsia 2012;53(12):2111-2119. https://doi.org/10.1111/j.15281167.2012.03649.x

12. Dravet C. The core Dravet syndrome phenotype. Epilepsia 2011;52(s2):3-9. https://doi.org/10.1111/ j.1528-1167.2011.02994.x

13. Myers KA, Scheffer IE, Berkovic SE. Genetic literacy series: Genetic epilepsy with febrile seizures plus. Epileptic Disord 2018;20(4):232-238. https://doi.org/10.1684/epd.2018.0985

14. Myers KA, Johnstone DL, Dyment DA. Epilepsy genetics: Current knowledge, applications, and future directions. Clin Genet 2019;95(1):95-111. https://doi.org/10.1111/cge.13414

15. Perucca P, Perucca E. Identifying mutations in epilepsy genes: Impact on treatment selection. Epilepsy Res 2019;152:18-30. https://doi.org/10.1016/..eplepsyres.2019.03.001

16. Howell KB, Eggers S, Dalziel K, et al. A population-based cost-effectiveness study of early genetic testing in severe epilepsies of infancy. Epilepsia 2018;59(6):1177-1187. https://doi.org/10.1111/epi.14087

17. Sánchez Fernández I, Loddenkemper T, Gaínza-Lein M, Sheidley BR, Poduri A. Diagnostic yield of genetic tests in epilepsy: A meta-analysis and cost-effectiveness study. Neurology 2019;92(5):e418-e428. https://doi.org/10.1212/WNL.0000000000006850

18. Feigin VL, Forouzanfar MH, Krishnamurthi R, et al. Global and regional burden of stroke during 1990 - 2010: Findings from the Global Burden of Disease Study 2010. Lancet 2014;383(9913):245-255. https:// doi.org/10.1016/S0140-6736(13)61953-4

19. Esterhuizen AI, Carvill GL, Ramesar RS, et al. Clinical application of epilepsy genetics in Africa: Is now the time? Front Neurol 2018;9:276. https://doi.org/10.3389/fneur.2018.00276

20. Rotimi C, Abayomi A, Abimiku A, et al.; H3Africa Consortium. Enabling the genomic revolution in . Rotimi C, Abayomi A, Abimiku A, et al.; H3Africa Consortium. Enabling the gen
Africa. Science 2014;344(6190):1346-1348. https://doi.org/10.1126/science.1251546

21. Gulsuner S, Stein DJ, Susser ES, et al. Genetics of schizophrenia in the South African Xhosa. Science Gulsuner S, Stein DJ, Susser ES, et al. Genetics of schizophrenia
2020;367(6477):569-573. https://doi.org/10.1126/science.aay8833

22. Esterhuizen AI, Mefford HC, Ramesar RS, Wang S, Carvill GL, Wilmshurst JM. Dravet syndrome in South African infants: Tools for an early diagnosis. Seizure 2018;62:99-105. https://doi.org/10.1016/j. seizure.2018.09.010

S Afr Med J 2021;111(1):8-9. https://doi.org/10.7196/SAMJ.2021.v111i1.15365 